\title{
Parental alcohol misuse and hazardous drinking among offspring in a general teenage population: gender-specific findings from the Young-HUNT 3 study
}

Siri H Haugland ${ }^{1 *}$, Turid L Holmen ${ }^{1}$, Edle Ravndal ${ }^{3}$ and Grete H Bratberg ${ }^{1,2}$

\begin{abstract}
Background: Parental alcohol misuse may negatively affect drinking behaviours among offspring, but it is unclear to what extent influences are gender-specific and dependent upon the actual drinking behaviour measured. The aim of this study was to investigate whether hazardous drinking among Norwegian teenage boys $(\mathrm{N}=2538)$ and girls ( $N=2494)$ was associated with paternal and maternal alcohol misuse (CAGE).

Methods: Definitions of hazardous drinking among offspring were based on self-reported alcohol consumption (in litres a year), frequency of drinking, and frequency of drunkenness. Based on this information, two composite measures of hazardous drinking were also constructed. Cross-sectional data from the Norwegian Young-HUNT 3 survey (2006-2008) were linked to information from biological parents who participated in the adult part of the HUNT study.

Results: Logistic regression analyses showed that both boys and girls with alcohol misusing fathers were more likely to report high levels of alcohol intake compared to others of the same age and gender. This was contrary to boys with misusing mothers, who reported less alcohol consumption than other boys. Among girls, but not boys, high frequency of drunkenness was associated with maternal as well as paternal misuse.

Conclusions: This study suggests that adolescent hazardous drinking is more prevalent among boys and girls with alcohol misusing parents versus those whose parents do not misuse alcohol. However, findings were gender specific and varied depending on the drinking outcomes under investigation. More evidence-based knowledge in this field is of great importance for better understanding the possible role paternal and maternal alcohol misuse may play in the development of hazardous alcohol drinking patterns among adolescent boys and girls.
\end{abstract}

Keywords: Adolescence, Parents, Alcohol consumption, Alcohol misuse, Gender, Generations, Family, Environment

\section{Background}

Harmful alcohol use is a major contributor to the global burden of disease, premature deaths, disabilities, and neuropsychiatric disorders. Alcohol misuse can be related to both chronic disease and acute injury, in addition to social, psychological, and economical harm [1-4]. Initiation of alcohol use during adolescence is prevalent both in

\footnotetext{
* Correspondence: siri.h.haugland@ntnu.no

'HUNT Research Center, Department of Public Health and General Practice, Faculty of Medicine, Norwegian, University of Science and Technology, Forskningsveien 2, Levanger 7600, Norway

Full list of author information is available at the end of the article
}

Norway and in many Western countries [5,6]. The 2011 ESPAD report demonstrates that, even though Norwegian adolescents reported less drug and alcohol use than adolescents in the majority of the participating European countries, the average amount of alcohol consumed during the most recent drinking day was among the top three highest levels [7]. Alcohol is also commonly used among Norwegian adults [8].

Alcohol epidemiology has traditionally focused on consumption volume, but in recent years drinking patterns such as frequent drinking and heavy episodic drinking (including binge drinking and intoxication) have gained

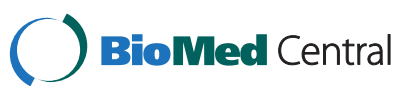


increased attention [9]. Hazardous drinking can be defined as a pattern of alcohol use that increases the risk of harmful consequences for the user [10]. Volume of consumption has been associated with numerous diseases in a doseresponse relationship $[3,4,11]$. Other studies found that frequent drinking at 14-15 years of age predicts alcohol dependence at ages 20-21 [12], while heavy episodic drinking typically has been related to short-term acute injuries that may be fatal [13].

Hazardous drinking becomes more prevalent with age during adolescence. Several factors may increase the likelihood of hazardous alcohol consumption, such as hereditary predisposition, impaired parenthood, parental divorce, social deprivation, risky use among peers, early pubertal timing, and mental health and behavioural problems [14-19].

A history of alcohol misuse in the family may also increase the risk of hazardous drinking in adolescence [18,20-25]. WHO's European regional office estimated in 1998 that 4.5 million young people in the EU region lived in families adversely affected by alcohol [26]. In Norway it has been estimated that $8.3 \%$ of children live in homes where at least one of the parents suffer from an alcohol use disorder [27].

Although there is well-established research regarding the effects that familial alcohol use disorder has on offspring's risk of problematic drinking, a large part of the studies on children with parents who abuse alcohol has relied on clinical samples. This may have led to an overestimation of adverse consequences due to the selection of more severely impaired parents [24]. Using population-based samples may contribute to expanding existing knowledge about the consequences of parental alcohol misuse on offspring drinking patterns in the general population.

It is unclear whether parental and offspring gender may be of importance for the association between parental and offspring alcohol use, and findings of possible gender effects have been inconclusive [28-32]. Lieb et al. [28] found that the impact of parental alcohol use disorders was comparable for male and female offspring, but consequences depended on the gender of the misusing parent. While maternal alcohol misuse was associated with a higher risk of progression from occasional to regular use, paternal alcohol misuse was associated with progression from regular to hazardous use. Zwaluw et al. [33] found that maternal, but not paternal, problem drinking was associated with alcohol use among the oldest adolescents (16-17 years of age). Paternal problem drinking was, however, associated with alcohol use in younger adolescents (14-15 years of age). A recent study [34] found that female college students with alcohol misusing mothers had greater risk of problematic alcohol consumption compared to those with alcohol misusing fathers.
Other studies have failed to prove gender as an important factor in response to parental alcohol problems [35]. Some of the inconsistency in gender-specific findings regarding parental alcohol misuse and gender might be due to the great variety of study designs, sample sizes, and measurements, making it difficult to compare findings across studies. Another challenge for comparisons is that drinking patterns largely differ between countries and cultures. Studies including both parental gender and offspring gender are needed for a better genderspecific understanding of the relationship between parental alcohol misuse and hazardous drinking among adolescent offspring [36].

The aims of this study were to investigate whether hazardous drinking in a sample from the general population of adolescents at 13-19 years of age was associated with biological mother's and/or father's alcohol misuse, and whether possible associations were related to offspring gender.

\section{Methods}

\section{Design and participants}

This study combines data from adolescents and their biological parents who participated in the youth or adult part of the third wave of the Nord-Trøndelag Health Study (Young-HUNT 3 or HUNT 3, 2006-2008). All inhabitants aged 13 years or older and living in NordTrøndelag (the central Norwegian county with approximately 127,000 inhabitants) were invited to participate. Adult participants completed self-report questionnaires (somatic and mental health, lifestyle, quality of life, use of medication, use of health services) and attended clinical examinations ${ }^{\mathrm{a}}$. Parental alcohol consumption was reported in two different questionnaires (Q1 and Q2), where alcohol misuse (CAGE) was included in Q2. The response rate for Q1 was 54\% ( $=50807)$, of whom about $80 \%$ responded to Q2 (i.e. 27,758 women and 23,049 men). For more information about the HUNT 3 survey, see Krokstad et al. [37].

The youth part of HUNT 3 (Young-HUNT 3) was conducted in school settings, and the students completed a self-administered questionnaire during one school hour. All students in junior and senior high schools, aged 1319 years, were invited to participate. Adolescents outside the school system were identified through lists obtained from the local authorities. In the Young-HUNT3 survey, 8200 participants (78\% response rate) completed the questionnaire [38], where 115 of the participants were obtained outside the school system [38]. In this study we included 5032 (61\%) students who could be linked to either biological mother's and/or father's responses (questionnaire 2) in the HUNT 3 survey. Through the Norwegian Family Register, using the 11-digit personal number given to every Norwegian at birth, it was possible to merge data between 4174 adolescents and their biological mothers, and between 
3123 adolescents and their biological fathers. A higher proportion of the adolescents had data from mothers compared to fathers ( $83 \%$ vs. $62 \%)$. Nearly half $(45 \%)$ of the study population had information from both biological parents (Table 1). An equal proportion of boys $(n=2538)$ and girls $(\mathrm{n}=2494)$ were included.

When considering the possibilities of selection bias, we made some comparisons between those included (with parental data) and those excluded (without parental data). We found no statistically significant differences in the prevalence of hazardous drinking behaviour between the groups, but parental divorce was more common among those excluded than among those included ( $24.4 \%$ vs. $35.5 \%$, $\mathrm{p}<.001$ ), and those excluded were also on average slightly younger ( 15.8 years vs. 15.9 years, $p=0.047$ ). Details are included in Additional file 1.

\section{Measures}

Measuring alcohol consumption patterns among adolescents entailed questions about frequency of drinking, number of intoxication events, and beverage-specific alcohol consumption.

As alcohol consumption becomes more prevalent with age, we used age dependent cutoffs (i.e. relative to peers of same age) to define frequent drinking, frequent intoxication and high level of alcohol consumption.

Students who initially reported never consuming alcohol or not knowing if they had ever tried alcohol were asked to pass additional questions about alcohol use. Missing data due to this initial question was recorded as "no use" in the dataset, but if respondents reported alcohol use in later parts of the questionnaire, the latter response was held as valid.

\section{Frequent drinking}

Students were asked "How often do you usually drink alcohol", with five response categories from never to every week or more often. Students in lower secondary school who drank alcohol "every other week or more often" and students in upper secondary school who "drank every week or more often" were defined as frequent drinkers (coded 1). Other responses were coded 0.

\section{Frequent intoxication episodes}

The number of lifetime alcohol intoxication episodes had five response alternatives: Never, once, 2-3 times, 4-10 times, 11-25 times, or more than 25 times.

Any intoxication episode reported by $13-14$ year olds, four episodes or more reported by 15 year olds, ten episodes or more reported by 16 year olds, and 25 episodes or more episodes reported by 17-19 year olds were classified as frequent intoxication episodes (coded 1). Other responses were coded 0 .

\section{High levels of alcohol consumption}

Information about alcohol consumption was based on students' reports of how much beer, wine, and liquor they

Table 1 Characteristics and descriptive statistics of the adolescents and parents included in the study sample, by gender

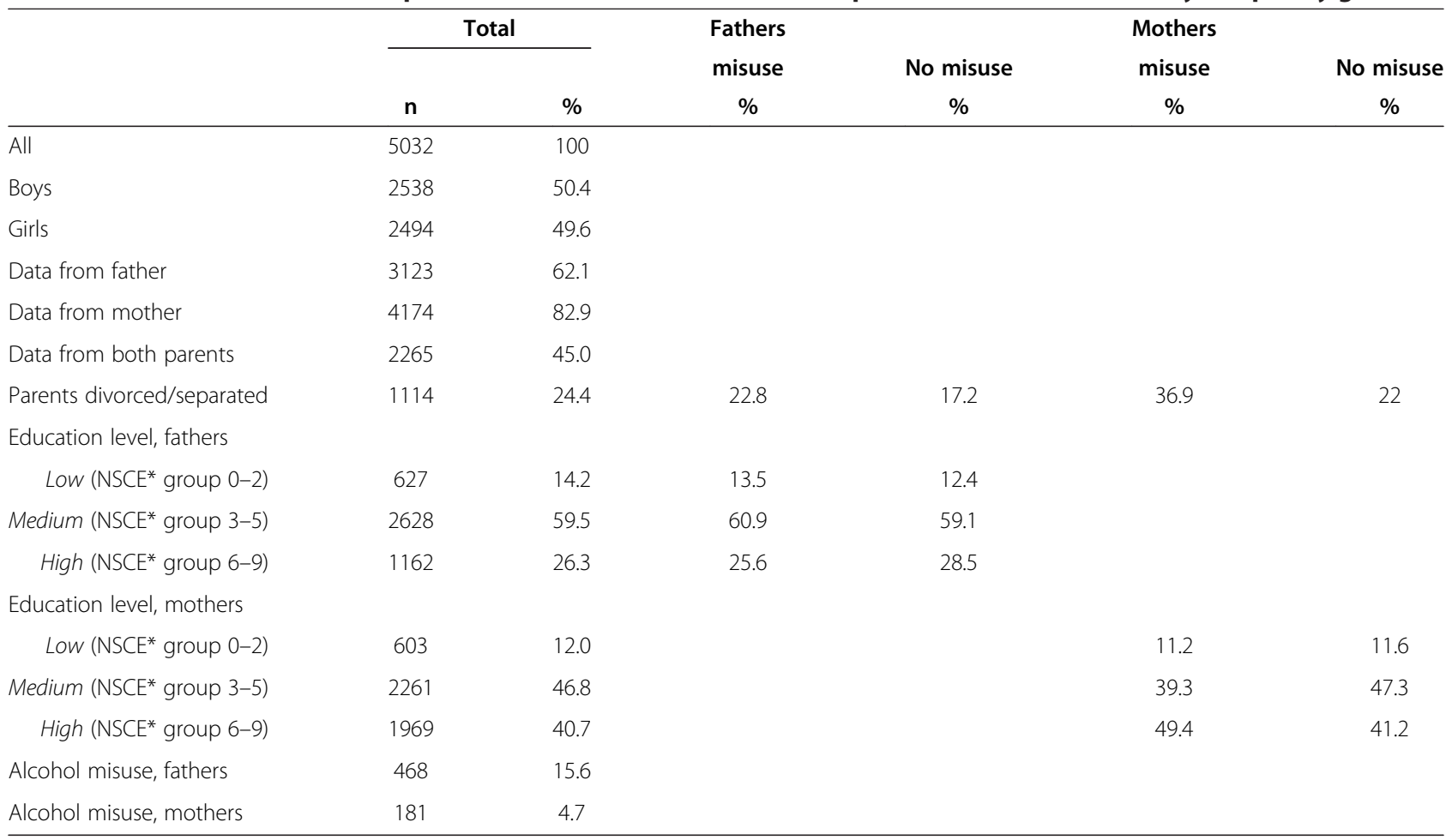

*Norwegian Standard Classification of Education. 
usually drank during a period of two weeks, calculated into litres of pure alcohol a year. Adolescents with consumption above the 75th percentile within each age and gender group were coded 1 ; others were coded 0 .

\section{Composite measurement of hazardous drinking}

Based on the underlying assumption that adolescents who report several types of hazardous alcohol behaviours are at greater risk of harm than adolescents who report fewer or none, we constructed a composite "hazardous drinking" variable consisting of the three items described above (frequent drinking, frequent intoxication episodes, and/or high consumption levels), with a maximum score of 3 . A score of 1 was categorized as "moderately hazardous" and 2 or 3 were categorized "highly hazardous". In multivariate analyses, moderately and highly hazardous drinkers were compared separately with those without any of the hazardous drinking behaviours (coded 0 ).

\section{Parental alcohol misuse}

Parental alcohol misuse was measured by the four items of the CAGE questionnaire [39]. CAGE is one of the most widely validated screening tools for detecting alcohol abuse and dependence in primary care. Standard CAGE consists of four items: 1) Have you ever felt that you ought to Cut down on your drinking? 2) Have people Annoyed you by criticizing your drinking? ${ }^{\text {b }}$ 3) Have you ever felt bad or Guilty about your drinking? 4) Have you ever had a drink first thing in the morning to steady your nerves or to get rid of a hangover (Eye-opener)? CAGE has demonstrated high test-retest reliability (0.80-0.95) [40]. Skogen et al. [41] examined the concurrent validity of the CAGE questionnaire in previous HUNT studies and found the internal validity of CAGE to be adequate (Kuder Richardson 0.68). They also found a linear relationship between both current and previous excessive alcohol consumption.

The standardized and recommended cut-point for the CAGE instrument to screen for alcohol abuse and dependence was applied [40]. CAGE scores of $\geq 2$ was coded 1 (misuse); those below 2 were coded 0 (no misuse). Parents who reported abstention in Q1 combined with not answering any of the four CAGE questions (Q2) were coded 0 (no misuse). In order to include those with incomplete data (i.e. 1-3 CAGE items), missing data on one or more CAGE items were coded 0 . Since CAGE is not a diagnostic tool, the term "misuse" was used for respondents with a score of 2 or higher.

\section{Confounders}

Parental education, parental divorce/separation, parental depression/anxiety, and adolescent age at screening point were considered as possible confounders [42-46]. Data on parental educational status (year 2008) was retrieved from the Norwegian education register (Statistics Norway) and linked to the data.

Educational status was categorized into nine levels of education according to the Norwegian Standard Classification of Education/NSCE [47] and used as a continuous variable in multivariate analyses. Information about parental divorce/separation was based on adolescent self-reports that parents had been divorced or separated for more than one year. Adolescent age was included as a continuous variable in the multivariate analyses. Parental depression/anxiety was measured through parental report using the Hospital Anxiety and Depression Scale (HADS) [48].

\section{Statistical procedure}

Initial descriptive analyses were performed for obtaining an overview of the data. The main dependent variable in this study was "hazardous alcohol drinking", defined as frequent drinking, frequent intoxication episodes, or high consumption levels, in addition to the composite measures moderately or highly hazardous drinking behaviours. To investigate if hazardous alcohol consumption was more common among boys and girls with alcohol misusing parents (mothers or fathers) compared to others of the same age, we used multivariate logistic regression analyses. Results were reported as odds ratios (ORs) with 95\% confidence intervals (CIs) and with the respective p-values, with a significance level set to $0.05(P)$. Since the initial analyses revealed statistically significant interactions across genders, analyses were stratified and conducted separately for boys and girls for each of their parents. In the multivariate regression models, odds ratios were adjusted for the possible confounding of adolescent's age, parental marital status, and education level.

\section{Ethics}

All participants, and in addition the guardians of participants under the age of 16 , gave their written consent. The study was approved by the Norwegian Data Inspectorate and the Regional Committee for Medical Research Ethics (REK).

\section{Results}

\section{Descriptive statistics}

In this study 2538 boys and 2494 girls with data from one or both parents were included (Table 1). About one fourth of the respondents reported that their parents had been divorced/separated for more than one year, and among these respondents, half cohabited mostly with their mother, while $37 \%$ cohabited equally with both parents or mostly with their father (13\%). As Table 1 illustrates, more mothers than fathers had a higher education (41\% vs. $26 \%$ ), and paternal alcohol misuse was more common (16\%) than maternal misuse $(5 \%)$. 
Frequency of hazardous drinking behaviours by status of parental alcohol misuse

Table 2 shows that the frequency (\%) of the defined hazardous drinking behaviours differs to some extent between each of the behaviours, but that proportions were fairly similar for both genders. Relatively more boys than girls were classified as frequent drinkers.

\section{Adolescent hazardous drinking associated with parental alcohol misuse}

Tables 3 and 4 reveal the crude and multivariate adjusted odds ratios (ORs) of hazardous alcohol drinking behaviours among adolescents with alcohol misusing parents compared to those without misusing parents (reference group), stratified by both parental as well as offspring gender.

\section{High levels of alcohol consumption}

Alcohol consumption levels above the 75th percentile for each age group and gender were more common among boys $(\mathrm{OR}=1.6 ; \mathrm{CI}=1.1-2.3)$ and girls $(\mathrm{OR}=1.5 ; \mathrm{CI}=1.1-2.1)$ with alcohol misusing fathers versus those offspring with non-misusing fathers (Table 3, adjusted model). High levels of alcohol consumption were less common among boys with alcohol misusing mothers $(\mathrm{OR}=0.2 ; \mathrm{CI}=0.1-0.6)$ compared to other boys.

\section{Frequent intoxication episodes}

Girls with maternal $(\mathrm{OR}=1.8 ; \mathrm{CI}=1.0-3.1)$ or paternal $(\mathrm{OR}=1.5 ; \mathrm{CI}=1.1-2.1)$ alcohol misuse were more likely than other girls to report high frequency of intoxication (Table 3). Frequent intoxication episodes in boys were not associated with either maternal or paternal alcohol misuse.

\section{Frequent drinking}

Frequent drinking among boys was associated with paternal alcohol misuse in bivariate analyses, but in multivariate adjusted analyses this association was no longer statistically significant (Table 3). Frequent drinking among girls was not associated with parental alcohol misuse.

\section{Composite hazardous drinking measurement}

Moderately hazardous drinking was associated with paternal alcohol misuse for girls $(\mathrm{OR}=1.9 ; \mathrm{CI}=1.3-2.8)$, but not for boys (Table 4). Highly hazardous drinking was associated with paternal alcohol misuse for boys $(\mathrm{OR}=1.7$; $\mathrm{CI}=1.2-2.5$ ), but not for girls (Table 4).

\section{Confounders}

High parental education was in most models significantly associated with a reduction in the OR of adolescent hazardous drinking, while divorce/separation and adolescent age increased the OR of hazardous drinking. The associations between the confounding variables and different outcomes varied to some extent depending on both parental and offspring gender. Details on this are included as supplementary material in Tables S6 and S7 found in the Additional file 1. Initial analyses included the Hospital Anxiety and Depression Scale as a possible confounder (HADS-A and HADS-D). Since we found very little evidence for an association between parental anxiety and depression and the different outcomes under investigation, HADS was excluded in the multivariate models.

\section{Discussion}

Our findings verify previous studies showing that alcohol misuse among parents increases the likelihood of hazardous drinking among offspring $[21,28,49]$. However, results varied depending on gender and the actual drinking behaviours investigated. High levels of alcohol consumption were more common among both boys and girls when their fathers misused alcohol, while it was a tendency that boys with misusing mothers reported less hazardous drinking,

Table 2 The number and proportion of various hazardous drinking behaviours among boys and girls by status of paternal and maternal alcohol misuse

\begin{tabular}{|c|c|c|c|c|c|c|c|c|c|c|c|}
\hline \multirow[t]{3}{*}{ Hazardous drinking behaviours } & & \multicolumn{2}{|l|}{ Total } & \multicolumn{4}{|c|}{ Fathers } & \multicolumn{4}{|c|}{ Mothers } \\
\hline & & \multirow[b]{2}{*}{ n (total) } & \multirow[b]{2}{*}{$\%$} & \multicolumn{2}{|c|}{ Misuse } & \multicolumn{2}{|c|}{ No misuse } & \multicolumn{2}{|c|}{ Misuse } & \multicolumn{2}{|c|}{ No misuse } \\
\hline & & & & n (total) & $\%$ & n (total) & $\%$ & n (total) & $\%$ & n (total) & $\%$ \\
\hline \multirow[t]{2}{*}{ High alcohol consumption } & Boys & $479(2371)$ & 20.2 & $49(192)$ & 25.5 & $232(1248)$ & 18.6 & $7(81)$ & 8.6 & $362(1754)$ & 20.6 \\
\hline & Girls & $496(2416)$ & 20.5 & $62(257)$ & 24.1 & $212(1174)$ & 18.1 & $26(90)$ & 28.9 & $371(1765)$ & 21 \\
\hline \multirow[t]{2}{*}{ Frequent intoxication } & Boys & 608 (1974) & 30.8 & $53(152)$ & 34.9 & 302 (1019) & 29.6 & $14(64)$ & 21.9 & 453 (1482) & 30.6 \\
\hline & Girls & $590(2162)$ & 27.3 & $77(234)$ & 32.9 & $274(1063)$ & 25.8 & $28(75)$ & 37.3 & 1029 (1482) & 27.6 \\
\hline \multirow[t]{2}{*}{ Frequent drinking } & Boys & $261(1981)$ & 13.2 & $31(156)$ & 19.9 & $128(1020)$ & 12.5 & $7(64)$ & 10.9 & 195 (1486) & 13.1 \\
\hline & Girls & $207(2161)$ & 9.6 & $19(233)$ & 8.2 & 95 (1066) & 8.9 & $9(74)$ & 12.2 & $152(1581)$ & 9.6 \\
\hline \multirow[t]{2}{*}{ Hazardous drinking, moderate } & Boys & $341(2055)$ & 16.6 & $26(154)$ & 17.9 & 169 (1087) & 15.5 & $9(77)$ & 11.7 & $271(1531)$ & 17.7 \\
\hline & Girls & $392(2138)$ & 18.3 & $57(222)$ & 25.7 & $182(1050)$ & 14.9 & $18(75)$ & 19.1 & $289(1556)$ & 15.7 \\
\hline \multirow[t]{2}{*}{ Hazardous drinking, high } & Boys & $414(2128)$ & 19.5 & $44(172)$ & 25.6 & $204(1122)$ & 18.2 & $9(77)$ & 11.7 & $304(1564)$ & 19.4 \\
\hline & Girls & 384 (2130) & 18 & $42(207)$ & 20.3 & 170 (1038) & 16.4 & $19(76)$ & 25 & 288 (1555) & 18.5 \\
\hline
\end{tabular}


Table 3 The odds ratios (ORs, $95 \% \mathrm{Cls}$ ) of various hazardous drinking behaviours among girls and boys by status of paternal and maternal alcohol misuse

\begin{tabular}{|c|c|c|c|c|c|c|c|c|c|c|c|c|}
\hline \multirow{3}{*}{$\begin{array}{l}\text { Outcomes } \\
\text { High alcohol consumption }\end{array}$} & \multirow{2}{*}{\multicolumn{2}{|c|}{ Exposures }} & \multicolumn{4}{|c|}{ Girls } & & & \multicolumn{4}{|c|}{ Boys } \\
\hline & & & \multirow{2}{*}{$\begin{array}{c}\mathbf{N}^{*} \\
1855\end{array}$} & \multirow{2}{*}{$\begin{array}{l}\text { OR } \\
1.5\end{array}$} & \multirow{2}{*}{$\frac{\mathrm{Cl}}{1.0-2.4}$} & \multirow{2}{*}{$\begin{array}{l}P \\
.078\end{array}$} & \multicolumn{2}{|c|}{ Exposures } & \multirow{2}{*}{$\begin{array}{c}\mathbf{N}^{*} \\
1835\end{array}$} & \multirow{2}{*}{$\begin{array}{l}\text { OR } \\
0.4\end{array}$} & \multirow{2}{*}{$\frac{\mathrm{Cl}}{0.2-0.8}$} & \multirow{2}{*}{$\begin{array}{c}P \\
.011\end{array}$} \\
\hline & Mother misuse & Crude & & & & & Mother misuse & Crude & & & & \\
\hline & & Adj. & 1714 & 1.3 & $0.8-2.3$ & .280 & & Adj. & 1662 & 0.2 & $0.1-0.6$ & .005 \\
\hline & Father misuse & Crude & 1431 & 1.4 & $1.0-2.0$ & .026 & Father misuse & Crude & 1440 & 1.5 & $1.1-2.1$ & .025 \\
\hline & & Adj. & 1341 & 1.5 & $1.1-2.1$ & .020 & & Adj. & 1336 & 1.6 & $1.1-2.3$ & .018 \\
\hline \multirow[t]{4}{*}{ Frequent intoxication } & Mother misuse & Crude & 1656 & 1.6 & $1.0-2.5$ & .068 & Mother misuse & Crude & 1546 & 0.6 & $0.3-1.2$ & .141 \\
\hline & & Adj. & 1528 & 1.8 & $1.0-3.1$ & .035 & & Adj. & 1395 & 0.6 & $0.3-1.1$ & .110 \\
\hline & Father misuse & Crude & 1297 & 1.4 & $1.0-1.9$ & .027 & Father misuse & Crude & 1171 & 1.3 & $0.9-1.8$ & .191 \\
\hline & & Adj. & 1221 & 1.5 & $1.1-2.1$ & .020 & & Adj. & 1093 & 1.4 & $1.0-2.1$ & .087 \\
\hline \multirow[t]{4}{*}{ Frequent drinking } & Mother misuse & Crude & 1655 & 1.3 & $0.6-2.7$ & .471 & Mother misuse & Crude & 1550 & 0.8 & $0.4-1.8$ & .612 \\
\hline & & Adj. & 1528 & 1.3 & $0.6-2.9$ & .454 & & Adj. & 1402 & 1.0 & $0.4-2.3$ & .963 \\
\hline & Father misuse & Crude & 1299 & 0.9 & $0.5-1.5$ & .711 & Father misuse & Crude & 1176 & 1.7 & $1.1-2.7$ & .014 \\
\hline & & Adj. & 1233 & 0.9 & $0.5-1.5$ & .665 & & Adj. & 1098 & 1.6 & $1.0-2.5$ & .059 \\
\hline
\end{tabular}

${ }^{*} \mathrm{~N}$ corresponds to the number of adolescents included in the analyses.

but these associations were statistically significant only for high alcohol consumption. Boys were more likely to report highly hazardous drinking (composite measurement) and girls moderately hazardous drinking when fathers misused alcohol. A high number of intoxication episodes were associated with both maternal and paternal alcohol misuse in girls, but not in boys.

\section{Genetic and environmental factors}

Both genetic and environmental factors have been found to be important for the etiology of alcohol consumption behaviours in adolescence [25,50,51]. While alcohol dependence in adulthood has been shown to have a strong heritable component, shared environmental influences seem to have a relatively stronger effect in youth samples and at earlier stages of alcohol use [25]. Throughout adolescence genetic factors gain importance [25] and may explain some of the variation in risky adolescent drinking.
A recent Swedish adoption study [52] concludes that drug abuse is an etiologically complex syndrome influenced by a diverse set of genetic risk factors and by a range of environmental factors, along with the interactions between these.

Parenting behaviour is considered to be an important environmental factor that partly explains the relationship between parental alcohol misuse and risky adolescent drinking. Parents who misuse alcohol have been found to provide less emotional support [53], have more problems with maintaining alcohol-specific behavioural control [33], and provide less monitoring [54]. Low levels of monitoring may facilitate more opportunities for offspring to establish risky drinking patterns. Other studies have failed to find parenting behaviours associated with parental problem drinking [33].

Social learning theory [55] offers modelling as another possible explanation for transmission of drinking behaviour

Table 4 The odds ratios (ORs, 95\% Cl's) of moderate and high hazardous drinking (composite measure) among girls and boys by status of paternal and maternal alcohol misuse

\begin{tabular}{|c|c|c|c|c|c|c|c|c|c|c|c|c|}
\hline \multirow{3}{*}{$\frac{\text { Outcomes }}{\text { Hazardous drinking, moderate }}$} & & & \multicolumn{4}{|c|}{ Girls } & & & \multicolumn{4}{|c|}{ Boys } \\
\hline & \multicolumn{2}{|c|}{ Exposures } & \multirow{2}{*}{$\frac{N^{*}}{1631}$} & \multirow{2}{*}{$\frac{\text { OR }}{1.4}$} & \multirow{2}{*}{$\frac{\mathbf{C l}}{0.8-2.4}$} & \multirow{2}{*}{$\frac{P}{.242}$} & \multicolumn{2}{|c|}{ Exposures } & \multirow{2}{*}{$\frac{\mathbf{N}^{*}}{1608}$} & \multirow{2}{*}{$\frac{\text { OR }}{0.6}$} & \multirow{2}{*}{$\frac{\mathbf{C l}}{0.3-1.2}$} & \multirow{2}{*}{$\frac{P}{.179}$} \\
\hline & Mother misuse & Crude & & & & & Mother misuse & Crude & & & & \\
\hline & & Adj. & 1509 & 1.4 & $0.8-2.7$ & .255 & & Adj. & 1448 & 0.5 & $0.2-1.2$ & .138 \\
\hline & Father misuse & Crude & 1272 & 1.6 & $1.2-2.3$ & .004 & Father misuse & Crude & 1241 & 1.1 & $0.7-1.7$ & .670 \\
\hline & & Adj. & 1200 & 1.9 & $1.3-2.8$ & .001 & & Adj. & 1147 & 1.3 & $0.8-2.1$ & .331 \\
\hline \multirow[t]{4}{*}{ Hazardous drinking,high } & Mother misuse & Crude & 1631 & 1.5 & $0.9-2.5$ & .161 & Mother misuse & Crude & 1641 & 0.5 & $0.3-1.1$ & .096 \\
\hline & & Adj. & 1500 & 1.5 & $0.8-2.7$ & .211 & & Adj. & 1479 & 0.5 & $0.2-1.1$ & .103 \\
\hline & Father misuse & Crude & 1245 & 1.3 & $0.9-1.9$ & .172 & Father misuse & Crude & 1294 & 1.5 & $1.1-2.4$ & .022 \\
\hline & & Adj. & 1167 & 1.5 & $1.0-2.2$ & .077 & & Adj. & 1196 & 1.7 & $1.1-2.5$ & .016 \\
\hline
\end{tabular}

* $\mathrm{N}$ corresponds to the number of adolescents included in the analyses. 
across generations. A systematic review from 2010 [56] examined longitudinal studies of parenting factors associated with alcohol consumption in adolescents. Although results varied depending on age and gender, they found that children who had observed their parents consuming alcohol drank more as adolescents than those who had not. In a previous follow-up study of 13- to 14-year-old adolescents, we found that boys and girls who ever had observed their parents drunk also were more likely to report more hazardous drinking four years later [57].

\section{Aversive transmission}

Haller and Chassin [58] found that even though parental alcohol misuse mainly increased offspring drinking, there was evidence for aversive transmission. In accordance with that, we found that boys with misusing mothers were less likely than other boys to report high levels of alcohol consumption.

One possible mechanism for explaining aversive transmission is that offspring with parents who misuse alcohol may reduce their drinking due to their own self-perception of being at risk of future alcoholism [58]. Why maternal (and not paternal) alcohol misuse in our study was associated with decreased risk of high levels of alcohol consumption in boys and not in girls remains unexplained, but this should be a subject for further investigation.

\section{Gender-specific findings}

Research on possible consequences of having parents that misuse alcohol reveals heterogeneity in adverse outcomes associated with both parental gender and offspring gender [42,59-62]. Growing up with parents who misuse alcohol may have a different impact on boys and girls due to influences of both risk and protective environmental factors provided through culture, gender roles, education levels, and other factors. In our study, we found that parental alcohol misuse was associated with hazardous drinking behaviours among adolescents, but associations depended on both parental and offspring gender, as well as the outcomes under investigation.

When addressing gender-specific findings, several questions may arise. Does paternal alcohol misuse represent another kind of "threat" to offspring than maternal misuse, and are there gender-specific susceptibilities in children's responses to these exposures? Women are, for instance, more likely to use alcohol to self-medicate to cope with problems or traumas in their lives [42], and it has been suggested that maternal misusers exert negative influences of misuse to the child through emotional unavailability [63]. Paternal alcohol misuse, on the other hand, may influence their offspring negatively through other mechanisms, like more prevalent use of violence [42]. Lieb et al. [28] also suggest that fathers probably model more excessive drinking than mothers.
Possible mechanisms between parental and offspring alcohol consumption were beyond the scope of our study, but findings may suggest that alcohol misuse among fathers is more influential than it is among mothers, and that girls may be more susceptible to parental alcohol misuse than boys. Parental alcohol misuse was more often associated with various types of hazardous drinking behaviours in girls than in boys, while hazardous drinking behaviours among offspring more frequently were associated with paternal than maternal alcohol misuse. These differences could be random, but they are nonetheless interesting and may generate hypotheses about gender-specific differences that should be emphasized in future research.

\section{Limitations and strengths Limitations}

Since this study was cross-sectional, any interpretations of causality should be avoided. However, findings based on a large general population of teenage boys and girls as well as their biological parents may generate hypotheses about causal pathways.

There are several limitations associated with self-reported alcohol use and misuse that may have led to inaccuracy in measurements and underestimation of the associations between parental alcohol misuse and hazardous drinking among offspring. First, alcohol misusers tend to be underrepresented in surveys like this. Both heavy alcohol consumption and mental distress have been found to be moderately associated with non-response among adults [64]. In supplementary analyses of adolescents included in this study (with parental data), versus those excluded (without parental data), we found no differences related to hazardous drinking between the two samples. Associations were not severely affected by selective non-response.

An underrepresentation of parents who misuse alcohol will most likely underestimate the influence that parental alcohol use has on hazardous drinking among offspring. One should therefore also pay attention to associations of minor strength in studies like this.

Second, alcohol misuse in parents was not defined by the use of diagnostic tools, which may have led this study to inaccurately classify parental alcohol misuse [65]. On the other hand, several studies have found that CAGE as an instrument reliably assesses alcohol problems in the general population [66-68]. It should be noted that CAGE was phrased as lifetime-questions in this study, and thus refer to "ever" and not necessarily "current" alcohol misuse. The uncertainty regards the timing of alcohol misuse should be taken into account when interpreting the results.

In addition we were not able to include in the same model information on alcohol use for both parents. Therefore we could not differentiate the effect of having 
both parents misusing alcohol from the effect of having one parent misusing alcohol. We also did not have information on whether adolescents with parents who misuse alcohol live in the same household as the misusing parent. Thus we were unable to differentiate between adolescents who live in direct exposure and those raised in another environment. It would also have been desirable to apply multilevel analyses to account for possible dependency in the data, but this was not possible with our sample, as we did not have a common family-level identifier for the whole sample.

\section{Strengths}

Findings from this large representative study population of adolescents constitute an important supplement to previous studies, especially studies based on clinical samples. Moreover, few previous population-based studies have been able to link information independently reported by parents and their offspring. In contrast to many previous studies that have lacked female participants or had predominantly male representation in their materials, we were able to include both mothers and fathers. By including measures of both maternal and paternal alcohol misuse, and outcome measures from both female and male offspring, we were able to make gender-differentiated analyses and contribute new insights to this complex field of research.

\section{Conclusion}

Parental alcohol misuse is associated with an increased risk for hazardous drinking among offspring. Associations vary with both parental gender and offspring gender. Further research should elucidate possible gender-specific mechanisms that could contribute to these versatile findings. More evidence-based knowledge in this field is of great importance for both preventive and clinical practice among parents and adolescents who have a hazardous alcohol consumption pattern.

\section{Endnotes}

a (http://www.ntnu.no/hunt/english/data/que Retrieved 18.3.2013).

${ }^{\mathrm{b}}$ The question of CAGE applied in HUNT was phrased somewhat differently from the original: "Has someone ever criticized your drinking?".

\section{Additional file}

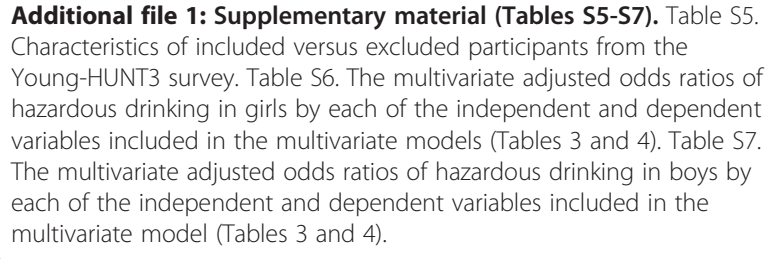

\section{Competing interests}

The authors declare that they have no competing interests.

\section{Authors' contributions}

$\mathrm{SHH}$ and GHB contributed significantly in all parts of the research process. TLH is the PI of the Young-HUNT Study. All co-authors have critically reviewed the process and provided suggestions for manuscript revisions. They have all read and approved the submitted manuscript.

\section{Acknowledgements}

The Nord-Trøndelag Health Study (HUNT Study) is a collaboration between HUNT Research Centre at the Faculty of Medicine, Norwegian University of Science and Technology (NTNU); Nord-Trøndelag County Council; Central Norway Health Authority; and the Norwegian Institute of Public Health. The study was funded by Samarbeidsorganet Helse Midt-Norge og NTNU/ the Liaison Committee between the Central Norway Regional Health Authority and NTNU. They had no further role in the study's design; in the collection, analysis, and interpretation of data; in the writing of the report; or in the decision to submit the paper for publication.

\section{Author details}

${ }^{1}$ HUNT Research Center, Department of Public Health and General Practice, Faculty of Medicine, Norwegian, University of Science and Technology, Forskningsveien 2, Levanger 7600, Norway. ${ }^{2}$ Department of Research and Development, Levanger Hospital, Health Trust Nord-Trøndelag, Levanger 7600, Norway. ${ }^{3}$ Norwegian Centre for Addiction Research, University of Oslo, P.O. Box 1039, Oslo, Blindern 0315, Norway.

Received: 26 June 2013 Accepted: 27 November 2013 Published: 6 December 2013

\section{References}

1. Babor T: Alcohol: no ordinary commodity - a summary of the second edition. Wiley; 2010. http://dx.doi.org/10.1111/j.1360-0443.2010.02945.x.

2. Rehm N, Room R, Edwards G, World Health Organization: Alcohol in the European region: consumption, harm and policies. Geneva: WHO; 2001.

3. World Health Organization Regional Office for Europe: Status report on alcohol and health in 35 European countries 2013. Copenhagen: World Health Organization Regional Office for Europe; 2013.

4. World Health Organization: Management of Substance Abuse Team: Global status report on alcohol and health. Geneva, Switzerland: World Health Organization; 2011.

5. Vedøy TF, Skretting A: Ungdom og rusmidler: resultater fra spørreskjemaundersøkelser 1968-2008. SIRUS: Oslo; 2009.

6. Hibell B, Skretting A: The 2007 ESPAD report: substance use among students in 35 European countries, vol. 2007. Stockholm, Sweden: The Swedish Council for Information on Alcohol and Other Drugs, CAN ; Council of Europe, Co-operation Group to Combat Drug Abuse and Illicit Trafficing in Drug (Pompidou Group); 2009.

7. Hibell B: The 2011 ESPAD Report: substance use among students in 36 European countries. Stockholm: The Swedish Council for Information on Alcohol and Other Drugs (CAN); 2012.

8. Horverak $\varnothing$, Bye EK: Det norske drikkemønsteret en studie basert på intervjudata fra 1973-2004. Oslo: SIRUS; 2007

9. Rehm J, Room R, Graham K, Monteiro M, Gmel G, Sempos CT: The relationship of average volume of alcohol consumption and patterns of drinking to burden of disease: an overview. Addiction 2003, 98(9):1209-1228.

10. World Health Organization: Lexicon of alcohol and drug terms. Geneva: World Health Organization; 1994.

11. Rehm J, Baliunas D, Borges GL, Graham K, Irving H, Kehoe T, Parry CD, Patra J, Popova S, Poznyak V, et al: The relation between different dimensions of alcohol consumption and burden of disease: an overview. Addiction 2010, 105(5):817-843.

12. Bonomo YA, Bowes G, Coffey C, Carlin JB, Patton GC: Teenage drinking and the onset of alcohol dependence: a cohort study over seven years. Addiction 2004, 99(12):1520-1528.

13. Rehm J, Taylor B, Patra J: Volume of alcohol consumption, patterns of drinking and burden of disease in the European region 2002. Addiction 2006, 101(8):1086-1095.

14. Strandheim A, Bratberg GH, Holmen $T L$, Coombes $L$, Bentzen N: The influence of behavioural and health problems on alcohol and drug use in late adolescence - a follow up study of 2399 young Norwegians. Child Adolesc Psychiatry Ment Health 2011, 5(1):17. 
15. Strandheim A, Holmen $T L$, Coombes L, Bentzen N: Alcohol use and physical health in adolescence: a general population survey of 8,983 young people in North-Trondelag, Norway (The Young-HUNT Study). Subst Use Misuse 2010, 45(1-2):253-265.

16. Bratberg GH, Nilsen TI, Holmen TL, Vatten LJ: Perceived pubertal timing, pubertal status and the prevalence of alcohol drinking and cigarette smoking in early and late adolescence: a population based study of 8950 Norwegian boys and girls. Acta Paediatr 2007, 96(2):292-295.

17. Rossow I, Kuntsche E: Early onset of drinking and risk of heavy drinking in young adulthood-a 13-year prospective study. Alcohol Clin Exp Res 2012, 37 Suppl1:E297-E304.

18. Geels LM, Vink JM, Van Beijsterveldt CE, Bartels M, Boomsma Dl: Developmental prediction model for early alcohol initiation in dutch adolescents. J Stud Alcohol Drugs 2013, 74(1):59-70.

19. Bratberg GH, Nilsen TI, Holmen TL, Vatten LJ: Sexual maturation in early adolescence and alcohol drinking and cigarette smoking in late adolescence: a prospective study of 2,129 Norwegian girls and boys. Eur J Pediatr 2005, 164(10):621-625.

20. Buchmann AF, Schmid B, Blomeyer D, Becker K, Treutlein J, Zimmermann US, Jennen-Steinmetz C, Schmidt MH, Esser G, Banaschewski T, et al: Impact of age at first drink on vulnerability to alcohol-related problems: Testing the marker hypothesis in a prospective study of young adults. J Psychiatr Res 2009, 43(15):1205-1212.

21. Wong MM, Nigg JT, Zucker RA, Puttler LI, Fitzgerald HE, Jester JM, Glass JM, Adams K: Behavioral control and resiliency in the onset of alcohol and illicit drug use: a prospective study from preschool to adolescence. Child Dev 2006, 77(4):1016-1033.

22. Johnson $\mathrm{J}$, Leff M: Children of substance abusers: overview of research findings. Pediatrics 1999, 103(5):1085-1099.

23. Latendresse SJ, Rose RJ, Viken RJ, Pulkkinen L, Kaprio J, Dick DM: Parenting mechanisms in links between parents' and adolescents' alcohol use behaviors. Alcohol Clin Exp Res 2008, 32(2):322-330.

24. Chassin L, Pitts SC, DeLucia C, Todd M: A longitudinal study of children of alcoholics: predicting young adult substance use disorders, anxiety, and depression. J Abnorm Psychol 1999, 108(1):106-119.

25. Lynskey MT, Agrawal A, Heath AC: Genetically informative research on adolescent substance use: methods, findings, and challenges. J Am Acad Child Adolesc Psychiatry 2010, 49(12):1202-1214.

26. Who: Global status report. In Alcohol and Young People. Edited by Jernigan DH. Geneva: World Health Organization; 2001.

27. Torvik FA, Rognmo K: Barn av foreldre med psykiske lidelser eller alkoholmisbruk. In Edited by Folkehelseinstitutt N. Oslo: Nasjonalt Folkehelseinstitutt; 2011.

28. Lieb R, Merikangas KR, Hofler M, Pfister H, Isensee B, Wittchen HU: Parental alcohol use disorders and alcohol use and disorders in offspring: a community study. Psychol Med 2002, 32(1):63-78.

29. Poelen EA, Engels RC, Scholte RH, Boomsma DI, Willemsen G: Predictors of problem drinking in adolescence and young adulthood. A longitudinal twin-family study. Eur Child Adolesc Psychiatry 2009, 18(6):345-352.

30. Coffelt NL, Forehand R, Olson AL, Jones DJ, Gaffney CA, Zens MS: A longitudinal examination of the link between parent alcohol problems and youth drinking: the moderating roles of parent and child gender. Addict Behav 2006, 31(4):593-605.

31. Obot IS, Wagner FA, Anthony JC: Early onset and recent drug use among children of parents with alcohol problems: data from a national epidemiologic survey. Drug Alcohol Depend 2001, 65(1):1-8.

32. Seljamo S, Aromaa M, Koivusilta L, Rautava P, Sourander A, Helenius $H$, Sillanpaa M: Alcohol use in families: a 15-year prospective follow-up study. Addiction 2006, 101(7):984-992.

33. Van der Zwaluw CS, Scholte RH, Vermulst AA, Buitelaar JK, Verkes RJ, Engels RC: Parental problem drinking, parenting, and adolescent alcohol use. J Behav Med 2008, 31(3):189-200.

34. Pearson MR, D'Lima GM, Kelley ML: Maternal and paternal alcohol misuse and alcohol-related outcomes among college students. Subst Use Misuse 2012, 47(6):708-717.

35. Lynskey MT, Fergusson DM, Horwood LJ: The effect of parental alcohol problems on rates of adolescent psychiatric disorders. Addiction 1994, 89(10):1277-1286

36. Jenkins MB, Agrawal A, Lynskey MT, Nelson EC, Madden PA, Bucholz KK, Heath AC: Correlates of alcohol abuse/dependence in early-onset alcohol-using women. Am J Addict 2011, 20(5):429-434.
37. Krokstad S, Langhammer A, Hveem K, Holmen T, Midthjell K, Stene T, Bratberg G, Heggland J, Holmen J: Cohort profile: The HUNT Study, Norway. Int J Epidemiol 2012, 42(4):968-977.

38. Holmen TL, Bratberg G, Krokstad S, Langhammer A, Hveem K, Midthjell K Heggland J, Holmen J: Cohort profile of the Young-HUNT Study, Norway: a population-based study of adolescents. Int J Epidemiol 2013. Epub ahead of print.

39. Ewing JA: Detecting alcoholism. The CAGE questionnaire. JAMA 1984, 252(14):1905-1907.

40. Dhalla S, Kopec JA: The CAGE questionnaire for alcohol misuse: a review of reliability and validity studies. Clin Invest Med 2007, 30(1):33-41.

41. Skogen JC, Overland S, Knudsen AK, Mykletun A: Concurrent validity of the CAGE questionnaire. The Nord-Trondelag Health Study. Addict Behav 2011, 36(4):302-307.

42. Burke S, Shmied V, Montrose M, NSW Centre for Parenting and Research: Research to practice note. Ashfield, NSW: Centre for Parenting \& Research, NSW Department of Community Services; 2006. 1 electronic text (40p).

43. Strand $B H$, Steiro A: Alcohol consumption, income and education in Norway, 1993-2000. Tidsskr Nor Laegeforen 2003, 123(20):2849-2853.

44. Kristjansson AL, Sigfusdottir ID, Allegrante JP, Helgason AR: Parental divorce and adolescent cigarette smoking and alcohol use: assessing the importance of family conflict. Acta Paediatr 2009, 98(3):537-542.

45. Jeynes $W H$ : The effects of recent parental divorce on their children's consumption of alcohol. J Youth Adolescence 2001, 30(3):305-319.

46. Boden JM, Fergusson DM: Alcohol and depression. Addiction 2011, 106(5):906-914

47. SSB: Norwegian standard classification of education, Rev. 2000th edition. Oslo: Statistisk sentralbyrå (SSB); 2003.

48. Zigmond AS, Snaith RP: The hospital anxiety and depression scale. Acta Psychiatr Scand 1983, 67(6):361-370.

49. Sher KJ, Walitzer KS, Wood PK, Brent EE: Characteristics of children of alcoholics - putative risk-factors, substance use and abuse, and psychopathology. J Abnorm Psychol 1991, 100(4):427-448.

50. Molina BS, Donovan JE, Belendiuk KA: Familial loading for alcoholism and offspring behavior: mediating and moderating influences. Alcohol Clin Exp Res 2010, 34(11):1972-1984.

51. Miranda R Jr, Reynolds E, Ray L, Justus A, Knopik VS, McGeary J, Meyerson LA: Preliminary evidence for a gene-environment interaction in predicting alcohol use disorders in adolescents. Alcohol Clin Exp Res 2012. doi: 10.1111/ j.1530-0277.2012.01897.x.

52. Kendler KS, Sundquist K, Ohlsson H, Palmer K, Maes H, Winkleby MA, Sundquist $\mathrm{J}$ : Genetic and familial environmental influences on the risk for drug abuse: a national Swedish adoption study. Arch Gen Psychiatry 2012, 69(7):690-697.

53. Rutherford MJ, Cacciola JS, Alterman Al, McKay JR, Cook TJ: Young men's perceived quality of parenting based on familial history of alcoholism. J Child Adoles Subst 1997, 6(3):43-56.

54. Chassin L, Pillow DR, Curran PJ, Molina BS, Barrera M Jr: Relation of parental alcoholism to early adolescent substance use: a test of three mediating mechanisms. J Abnorm Psychol 1993, 102(1):3-19.

55. Bandura A: Social Foundations of Thought and Action: A Social Cognitive Theory. Englewood Cliffs, N.J.: Prentice-Hall; 1986.

56. Ryan SM, Jorm AF, Lubman DI: Parenting factors associated with reduced adolescent alcohol use: a systematic review of longitudinal studies. Aust N Z J Psychiatry 2010, 44(9):774-783.

57. Haugland SH, Strandheim A, Bratberg G: Is high-risk use of intoxicants more common among adolescents who have seen their parents intoxicated? Tidsskr Nor Laegeforen 2012, 132(4):410-413.

58. Haller MM, Chassin L: The reciprocal influences of perceived risk for alcoholism and alcohol use over time: evidence for aversive transmission of parental alcoholism. J Stud Alcohol Drugs 2010, 71(4):588-596.

59. Hussong AM, Zucker RA, Wong MM, Fitzgerald HE, Puttler LI: Social competence in children of alcoholic parents over time. Dev Psychol 2005, 41(5):747-759.

60. Rognmo K, Torvik FA, Ask H, Roysamb E, Tambs K: Paternal and maternal alcohol abuse and offspring mental distress in the general population: The Nord-Trondelag Health Study. BMC Public Health 2012, 12(1):448.

61. Grekin ER, Brennan PA, Hammen C: Parental alcohol use disorders and child delinquency: the mediating effects of executive functioning and chronic family stress. J Stud Alcohol 2005, 66(1):14-22.

62. Christensen HB, Bilenberg N: Behavioural and emotional problems in children of alcoholic mothers and fathers. Eur Child Adolesc Psychiatry 2000, 9(3):219-226. 
63. El-Sheikh M, Flanagan E: Parental problem drinking and children's adjustment: family conflict and parental depression as mediators and moderators of risk. J Abnorm Child Psychol 2001, 29(5):417-432.

64. Torvik FA, Rognmo K, Tambs K: Alcohol use and mental distress as predictors of non-response in a general population health survey: the HUNT study. Soc Psych Psych Epid 2012, 47(5):805-816.

65. Bisson J, Nadeau L, Demers A: The validity of the CAGE scale to screen for heavy drinking and drinking problems in a general population survey. Addiction 1999, 94(5):715-722.

66. Smart RG, Adlaf EM, Knoke D: Use of the CAGE scale in a population survey of drinking. J Stud Alcohol 1991, 52(6):593-596.

67. Chan AWK, Pristach EA, Welte JW: Detection by the CAGE of alcoholism or heavy drinking in primary care outpatients and the general population. J Subst Abuse 1994, 6(2):123-135.

68. Bataille V, Ruidavets JB, Arveiler D, Amouyel P, Ducimetiere P, Perret B, Ferrieres J: Joint use of clinical parameters, biological markers and cage questionnaire for the identification of heavy drinkers in a large population-based sample. Alcohol and Alcoholism 2003, 38(2):121-127.

doi:10.1186/1471-2458-13-1140

Cite this article as: Haugland et al:: Parental alcohol misuse and

hazardous drinking among offspring in a general teenage population: gender-specific findings from the Young-HUNT 3 study. BMC Public Health 2013 13:1140.

\section{Submit your next manuscript to BioMed Central and take full advantage of:}

- Convenient online submission

- Thorough peer review

- No space constraints or color figure charges

- Immediate publication on acceptance

- Inclusion in PubMed, CAS, Scopus and Google Scholar

- Research which is freely available for redistribution 